\title{
Vertical profile, contamination assessment of mercury and arsenic in sediment cores from typical intertidal zones of China
}

\author{
Chenchen Wang • Dawei Pan (D) - Haitao Han • \\ Xueping $\mathrm{Hu}$
}

Received: 6 December 2017 / Accepted: 16 May 2018

C) Springer International Publishing AG, part of Springer Nature 2018

\begin{abstract}
The vertical profiles, contamination levels, and potential ecological risks of mercury and arsenic were studied from the sediment cores of seven typical intertidal zones, including the Liaohe River Estuary, the Jianhe River Estuary, the Dagu River Estuary, Yancheng Shoal, the Dongtan Yangtze River Estuary, Hangzhou Bay, and the Pearl River Estuary. Marine sediment quality standards, the threshold effect level (TEL), and the probable effect level (PEL) were used as guidelines to evaluate sediment quality. In addition, the geo-accumulation index $\left(I_{\text {geo }}\right)$ and potential ecological risk index $\left(E_{r}^{i}\right)$ were used to assess contamination and potential ecological risks from mercury and arsenic. The results showed that the Pearl River Estuary was moderately polluted by mercury and represented a high potential ecological risk, while other areas were uncontaminated or mildly contaminated with low or moderate potential ecological risks. The Pearl River Estuary was mildly polluted by arsenic
\end{abstract}

Electronic supplementary material The online version of this article (https://doi.org/10.1007/s10661-018-6732-1) contains supplementary material, which is available to authorized users.

C. Wang $\cdot$ D. Pan $\cdot$ H. Han $\cdot$ X. Hu

Key Laboratory of Coastal Environmental Processes and Ecological Remediation, Yantai Institute of Coastal zone Research, Chinese Academy of Sciences, Chunhui Road 17, Yantai 264003, People's Republic of China

D. Pan $(\bowtie) \cdot X . H u$

University of Chinese Academy of Sciences, Beijing 100049,

People's Republic of China

e-mail: dwpan@yic.ac.cn and represented a mild potential ecological risk, while other areas were unpolluted and also posed a mild potential ecological risk.

Keywords Mercury · Arsenic · Sediment cores · Contamination assessment $\cdot$ Intertidal zones

\section{Introduction}

Mercury, as an important trace metal, has generated widespread concerns due to its high toxicity, persistence, bio-accumulation, and mobility, and it may produce adverse biological effects and toxicity in the environment (Zhang et al. 2017). Due to its particular chemical and physical characteristics, mercury can go through a variety of environmental reactions and processes, resulting in a complicated geochemical cycle. Mercury originating from anthropogenic and natural sources finally reaches marine environment (Araujo et al. 2017). Arsenic, as a toxic metalloid, has acute and chronic toxic carcinogenic effects on both aquatic and humans (Wang et al. 2016a). Elevated levels of arsenic are of particular concern because of their potential toxicity and prevalence (Gao et al. 2017). Arsenic is discharged into the environment through natural and anthropogenic activities, including emissions and wastewater from ore-mining and ore-processing industries, dye manufacture, tanneries, thermal power plants, and the application of certain insecticides and herbicides (Benzer 2017). Heavy metals, including mercury and arsenic released into environment, are eventually 
distributed between the aqueous phase and marine sediments through adsorption, hydrolysis, and coprecipitation (Delshab et al. 2017). Sediments are important sinks for heavy metals, which makes them useful in the assessment of metallic contamination (Sarasiab et al. 2014). For this reason, the evaluation of metal distribution and contamination in surface and core sediment is of vital importance to evaluate marine environments (Kumar et al. 2013).

As the interface of marine and terrestrial environments, intertidal zones have important hydrological and ecological functions and play crucial roles as habitats for tidal flat organisms and in the removal of aquatic pollution due to intensive industrial and agricultural activities and highly populated areas close to the coast (Qian et al. 2016). Pollutants such as surfactants, heavy metals, nutrients, oils, and persistent compounds discharged into intertidal zones can lead to serious environmental hazards (Traverso-Soto et al. 2015). Core sediments have proven to be an effective tool for establishing the effects of anthropogenic and natural processes on depositional environments, and they can be used to study the contamination history of aquatic ecosystems ( $\mathrm{Li}$ and $\mathrm{Li}$ 2017). Metals that enter aquatic systems are usually transported into sediments and can later be released to represent a secondary contamination source under changing environmental conditions ( $\mathrm{Gu}$ and Lin 2016). Therefore, sediments are both carriers and sources of heavy metal pollutants in marine systems. It is of vital importance to study the contamination levels and potential ecological risks of trace metals using sediment cores from intertidal zones.

To date, there have been many studies evaluating metal contamination and potential ecological risks in sediment cores from certain region, and they have mainly concentrated on the distribution, contamination, and chronology of heavy metals (Chen et al. 2016; Duan et al. 2013; Gu and Lin 2016; Wang et al. 2016b). However, few studies have focused on mercury and arsenic levels in sediment cores from typical intertidal zones of China, including the Liaohe River Estuary, the Jianhe River Estuary, the Dagu River Estuary, Yancheng Shoal, Hangzhou Bay, the Dongtan Yangtze River Estuary, and the Pearl River Estuary. Comprehensive research on the heavy metal pollution in sediment cores from these zones is still needed.

The following indices have been broadly applied to assess the degree of contamination of heavy metal contamination in sediments derived from human-made or natural sources and its potential biological effects: enrichment factor (EF), geo-accumulation index $\left(I_{\text {geo }}\right)$, pollution load index (PLI), potential ecological risk factor $\left(\mathrm{E}_{\mathrm{r}}^{\mathrm{i}}\right)$, modified pollution index (MPI), and more (Duodu et al. 2017). In this study, $I_{\text {geo }}$ and $\mathrm{E}_{\mathrm{r}}^{\mathrm{i}}$ were used to assess heavy metal contamination of heavy in view of the strengths and weaknesses of the two methods (Liu et al. 2016). The primary objectives of this study were to (1) estimate heavy metal contents (Flemming and Delafontaine 2000) and evaluate their contamination levels in typical intertidal sediment cores in China, (2) evaluate the potential ecological risks of heavy metals in sediment cores, and (3) analyze the distribution and possible sources of heavy metals in intertidal zones.

\section{Materials and methods}

\section{Study area}

China's eastern coastline is $18,000 \mathrm{~km}$ long with complex geology. The coastline spans various climate zones and is affected by different levels of economic development. Therefore, seven typical intertidal zones were selected as the study areas to explore the quality of sediments along China's eastern coastline. The intertidal zone of the Liaohe River Estuary, located in the southwest of Panjin, Liaoning Province, is the world's second largest coastal reed wetland area, belonging to a typical alluvial plain. The region is the home to the Liaohe oilfield and is affected by human activities, such as oil production and reclamation, causing serious environmental pollution and wetland degradation. The Jianhe River Estuary is located in the northeast of Tianjin, and is a typical intertidal zone under intensive influence of human activities due to the rapid development and large-scale reclamation. The Dagu River intertidal zone is located along the northern shore of Jiaozhou Bay in Qingdao, and is seriously affected by industrial and agricultural pollution. Yancheng Shoal in Jiangshu belongs to China's largest plain silt muddy tidal flat and exhibits clear zonal characteristics, making it convenient for comparing different sediment deposition areas and environmental quality. The Dongtan Yangtze River in Chongming is the largest and the most developed river mouth tidal mudflat wetland, with a complete distribution of tidal flat vegetation distribution, and is a typical river muddy intertidal zone in China. Hangzhou Bay, the most typical type of strong tidal bay silt mass 
intertidal zone, is located in the Qiantang River Estuary, a strong tidal estuary type. The Pearl River Estuary is one of China's earliest areas for industrialization, urbanization, and development, and is the area most affected by the human activities. Research on mercury and arsenic of sediment cores from typical intertidal zones can provide data support for the protection of the environment in intertidal zones.

Sediment sampling and pretreatment

Sediment cores were collected using a sediment corer with a length of about $100 \mathrm{~cm}$ and sliced at 2-cm interval immediately after collection with a plastic cutter, and then stored in clearly labeled polyethylene bags that were refrigerated at $-20{ }^{\circ} \mathrm{C}$ until laboratory analysis (Fig. 1). Of the cores from the seven typical intertidal zones, the sediment cores from the Liaohe River Estuary, the Jianhe River Estuary, and Yancheng Shoal were collected by the First Institute of Oceanography; sediment cores from the Dagu River Estuary was collected by the Ministry of Land and Resources of the Qingdao Institute of Marine Geology; sediment cores from Hangzhou Bay and the Dongtan Yangtze River Estuary were collected by the East China Normal University; and those from the Pearl River Estuary were collected by the Yantai Institute of Coastal Zone Research Chinese Academy of Sciences.

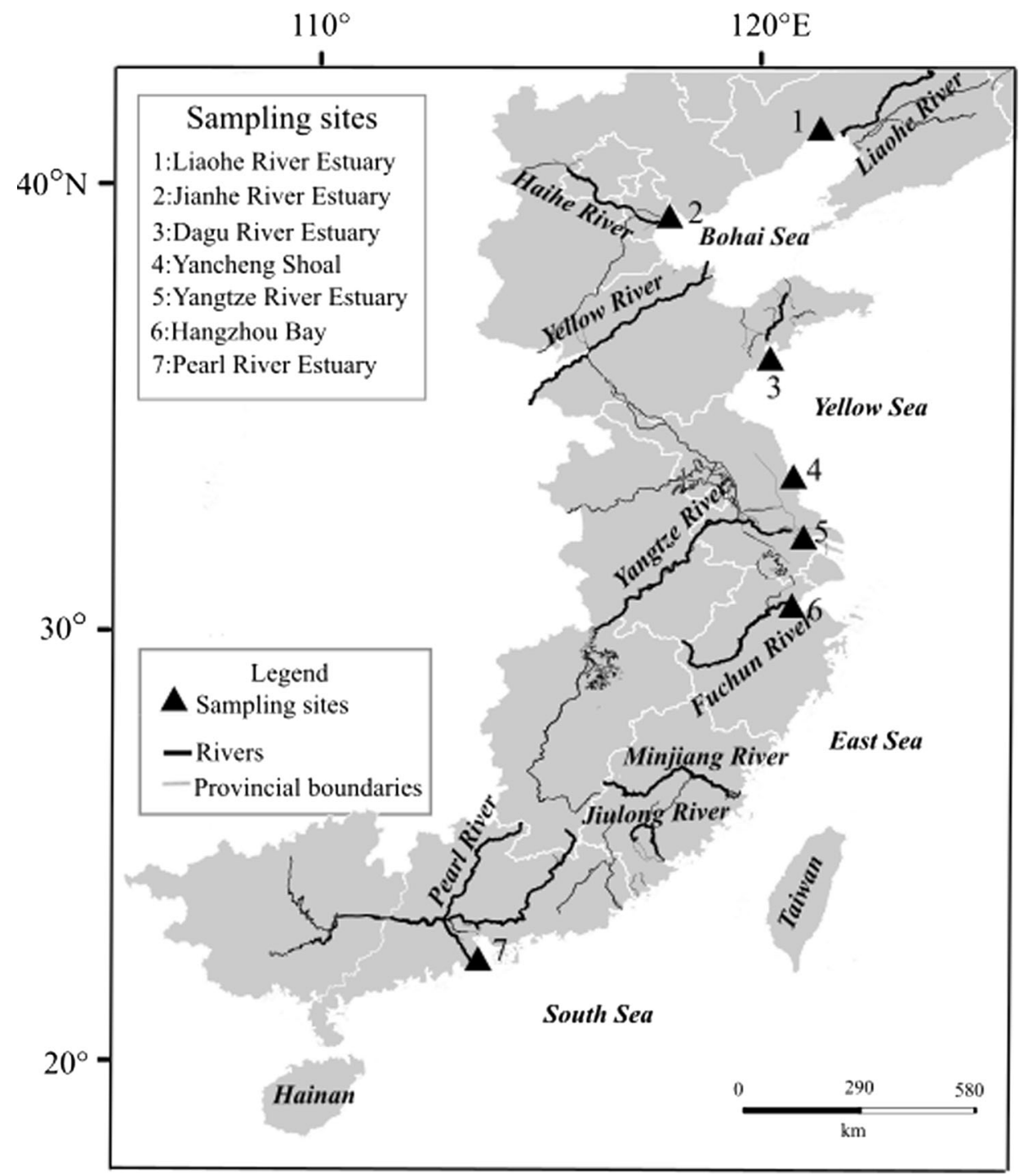

Fig. 1 Location of the study areas 
The frozen samples were dried in a lyophilizer (Germany Christ) and ground using an agate pestle and mortar, and then sieved through $95-\mu \mathrm{m}$ mesh for homogenization (AQSIQ 2007). The sediment samples were then digested using an acid mixture $\left(\mathrm{HCl}: \mathrm{HNO}_{3}: \mathrm{H}_{2} \mathrm{O}=1: 3: 5\right)$ in a boiling water bath and were finally analyzed using atomic fluorescence spectrometry (Beijing Ji Tian Instrument Co., AFS-930) for mercury and arsenic determination. A standard reference material (GBW07309) was used to assess measurement accuracy and the results were in accordance with reference values, and the results were listed in Table 1. Reagent blanks and sample replicates were also used for background correction and the verification of analysis precision. Due to the large quantity of samples, replicates were performed for every 10 sediment samples, which demonstrated that the analysis method was adequate. The basic data of sediment grain size, organic carbon contents, and sediment accumulation rates were shown in the supporting information (Tables S1 and S2). All glass and plastic utensils had been soaked overnight in $\mathrm{HNO}_{3}(10 \% v / v)$ and rinsed thoroughly with Milli-Q water prior to use. All reagents were guaranteed analytical reagent or at a higher level.

\section{Results and discussion}

Contents and vertical profiles of mercury and arsenic of sediment cores

The mercury contents of the intertidal sediment core from the Liaohe River Estuary ranged from 0.02 to $0.13 \mathrm{mg} / \mathrm{kg}$ and the average concentration was $0.07 \mathrm{mg} / \mathrm{kg}$ (Fig. 2 and Table 3), which was lower than the class I sediment category and the threshold effect level (TEL) (Table 2). This demonstrated that the mercury content of the intertidal sediment core from the Liaohe River Estuary was low and would be unlikely to cause negative biological effects. From the top to the bottom of the sediment core, the content of mercury had a tendency to increase at a depth of 0-38 cm, reaching the highest in the depth of $38 \mathrm{~cm}(0.13 \mathrm{mg} / \mathrm{kg})$, and the concentration of mercury decreased in the depth of 38 $110 \mathrm{~cm}$. Arsenic contents ranged from 5.79 to $13.48 \mathrm{mg} /$ $\mathrm{kg}$ and the average concentration was $9.98 \mathrm{mg} / \mathrm{kg}$ (Fig. 3 and Table 3), which was lower than the class I sediment category and higher than the TEL. These results implied that arsenic would have negative biological effects on the aquatic system. The arsenic content at $0-60-\mathrm{cm}$ depth was higher than that at $62-110-\mathrm{cm}$ depth, and contents varied little in both layers. These results revealed that the human-caused contributions of mercury and arsenic in the Liaohe River Estuary declined recently.

Mercury contents of the intertidal sediment core from Hangu the Jianhe River Estuary ranged from 0.03 to $0.08 \mathrm{mg} / \mathrm{kg}$ and the mean concentration was $0.03 \mathrm{mg} / \mathrm{kg}$ (Fig. 2 and Table 3), which was lower than the class I sediment category and TEL. These results implied that mercury would not cause negative biological effects on the surrounding aquatic systems. There was no clear change in mercury content except for the high value of $0.08 \mathrm{mg} / \mathrm{kg}$ at a depth of $24 \mathrm{~cm}$. Arsenic contents of the intertidal sediment core from the Jianhe River Estuary ranged from 8.60 to $15.76 \mathrm{mg} / \mathrm{kg}$ (Fig. 3 and Table 3) and the average concentration was $12.21 \mathrm{mg} / \mathrm{kg}$, which was lower than the class I sediment category and higher than the TEL. From the top to the bottom of the sediment core, the arsenic content tended to decrease and changed little within the depth range of 10 and $86 \mathrm{~cm}$. The vertical profiles of the mercury contents were relatively constant, whereas the concentration of arsenic decreased from the upper to lower layers in the depth of 0-14 cm, indicating that As had continuously accumulated in sediment in recent years.

The mercury contents of the intertidal sediment core in the Dagu River Estuary of Qingdao ranged from 0.01 to $0.06 \mathrm{mg} / \mathrm{kg}$ with an average concentration of $0.04 \mathrm{mg} / \mathrm{kg}$ (Fig. 2 and Table 3), far lower than the class I sediment category and the TEL. From the top to the
Table 1 Results of an analysis of certified reference materials (GBW07364)

\begin{tabular}{lllll}
\hline Element & GBW07364 & & \\
\cline { 2 - 5 } & Measured values & Certified values & $\begin{array}{l}\text { Standard } \\
\text { deviation (SD) }\end{array}$ & $\begin{array}{l}\text { Coefficient of } \\
\text { variation (CV\%) }\end{array}$ \\
\hline As & $19.20 \pm 1.90 \mathrm{mg} / \mathrm{kg}$ & $18.85 \mathrm{mg} / \mathrm{kg}$ & $0.53 \mathrm{mg} / \mathrm{kg}$ & 2.79 \\
$\mathrm{Hg}$ & $25.00 \pm 5.00 \mu \mathrm{g} / \mathrm{kg}$ & $24.00 \mu \mathrm{g} / \mathrm{kg}$ & $2.00 \mu \mathrm{gg} / \mathrm{kg}$ & 9.44 \\
\hline
\end{tabular}



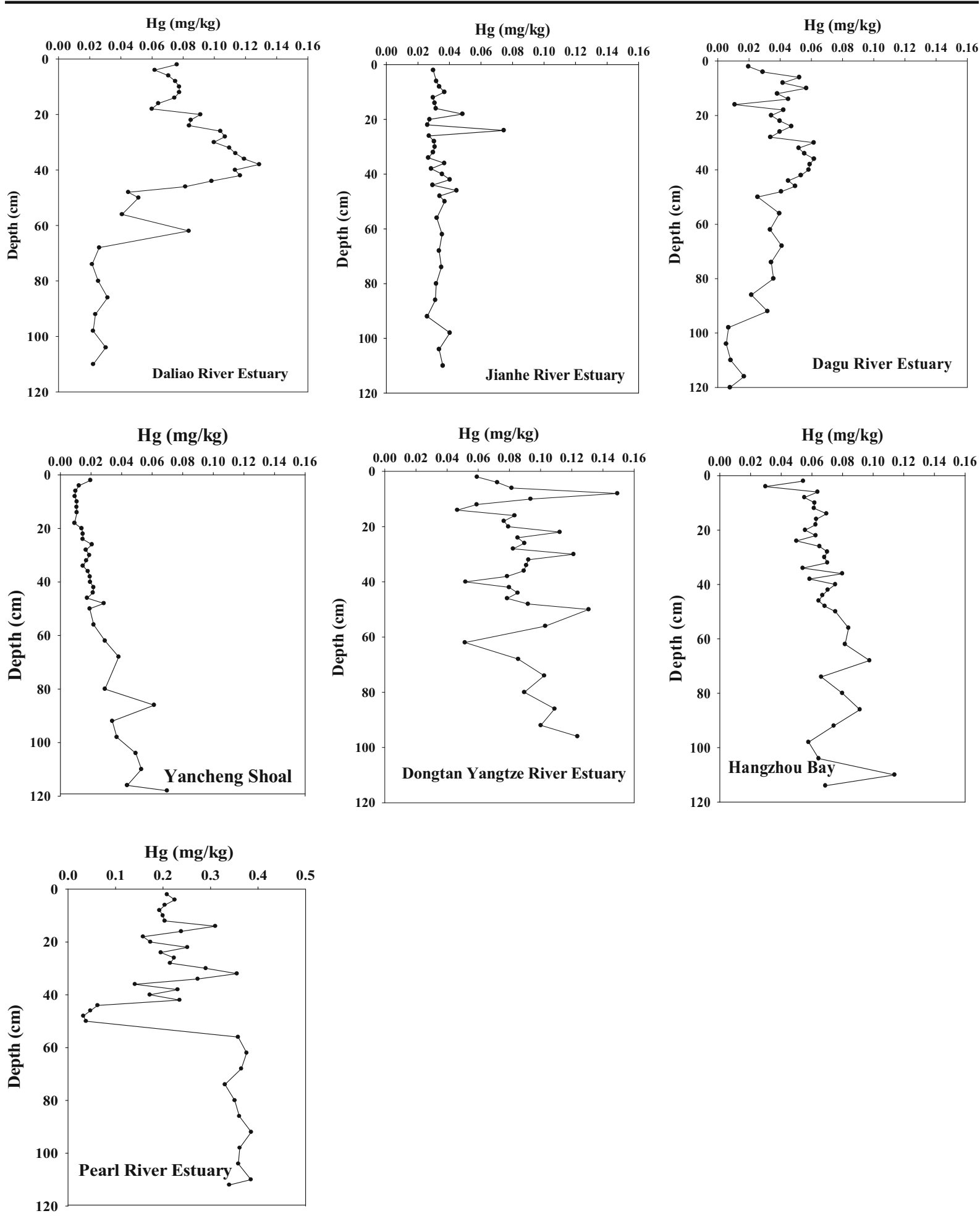

Fig. 2 Vertical profiles of mercury contents of sediment cores in seven typical intertidal zones

bottom of the sediment core, the mercury content tended to decrease and exhibited small variations in the depth of
0-40 $\mathrm{cm}$. Arsenic contents ranged from 5.40 to $12.19 \mathrm{mg} / \mathrm{kg}$ with an average concentration of 


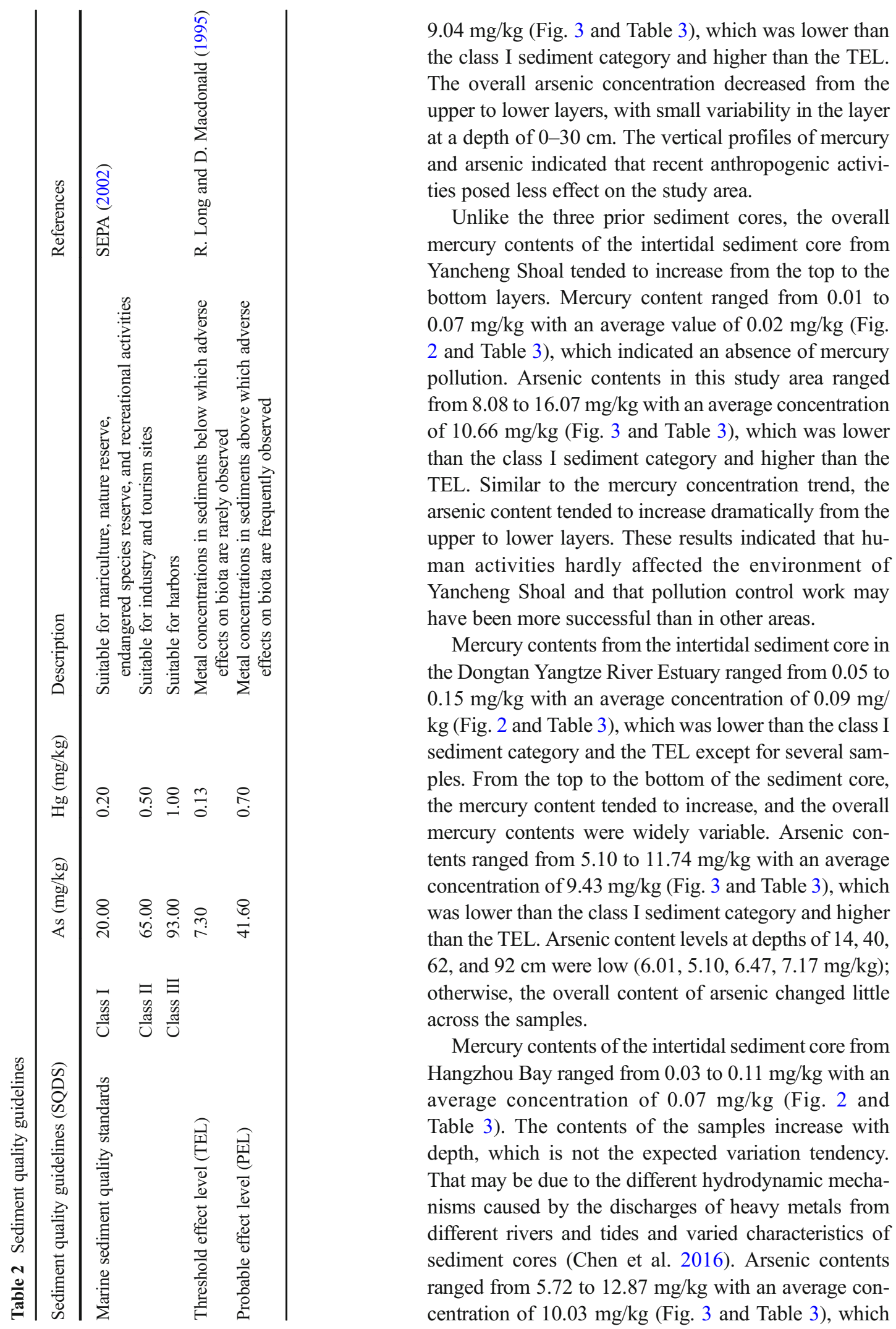



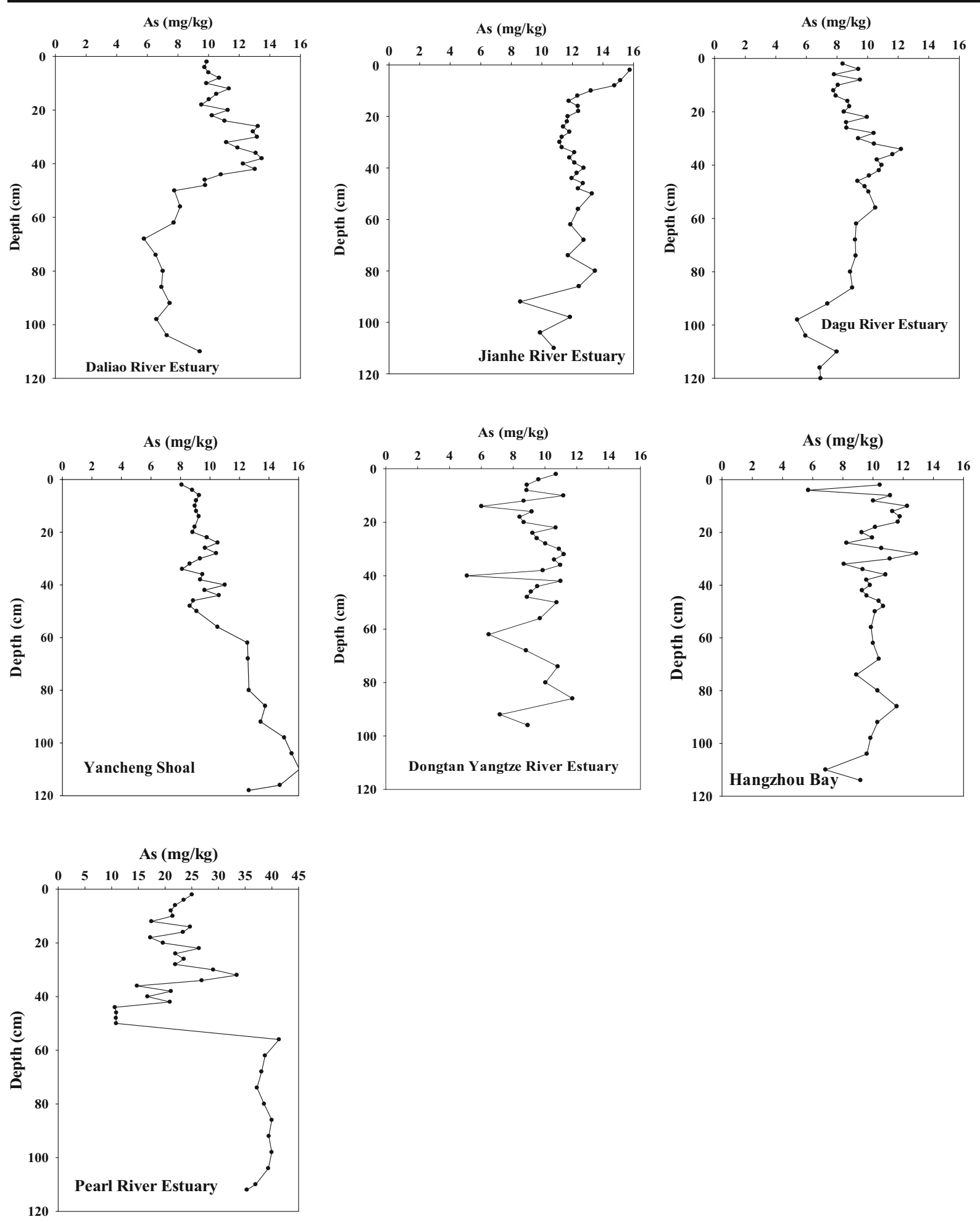

Fig. 3 Vertical profiles of arsenic contents of sediment cores in seven typical intertidal zones 
Table 3 Concentrations and background values of $\mathrm{Hg}$ and As in sediment cores of this study

\begin{tabular}{|c|c|c|c|c|c|c|c|}
\hline \multirow[t]{3}{*}{ Sampling sites } & \multicolumn{4}{|l|}{ This study } & \multicolumn{3}{|c|}{ Background value } \\
\hline & \multicolumn{2}{|l|}{$\mathrm{As}(\mathrm{mg} / \mathrm{kg})$} & \multicolumn{2}{|l|}{$\mathrm{Hg}(\mathrm{mg} / \mathrm{kg})$} & \multirow[t]{2}{*}{ As (mg/kg) } & \multirow[t]{2}{*}{$\mathrm{Hg}(\mathrm{mg} / \mathrm{kg})$} & \multirow[t]{2}{*}{ Reference } \\
\hline & Range & Mean & Range & Mean & & & \\
\hline Liaohe River Estuary & $5.79-13.48$ & 9.98 & $0.02-0.13$ & 0.07 & 9.00 & 0.19 & Ma et al. (2008) \\
\hline Jianhe River Estuary & $8.60-15.76$ & 12.21 & $0.03-0.08$ & 0.03 & 15.00 & 0.05 & Jiang et al. (2012) \\
\hline Dagu River Estuary & $5.40-12.19$ & 9.04 & $0.01-0.06$ & 0.04 & 9.30 & 0.02 & Centor (1990) \\
\hline Yancheng Shoal & $8.08-16.07$ & 10.66 & $0.01-0.07$ & 0.02 & 8.59 & 0.02 & Zuo et al. (2010) \\
\hline Dongtan Yangtze River Estuary & $5.10-11.74$ & 9.43 & $0.05-0.15$ & 0.09 & 7.57 & 0.13 & Tao et al. (2014) \\
\hline Hangzhou Bay & $5.72-12.87$ & 10.03 & $0.03-0.11$ & 0.07 & 9.99 & 0.04 & Chai et al. (2015) \\
\hline Pearl River Estuary & $10.62-41.35$ & 26.11 & $0.03-0.39$ & 0.25 & 10.00 & 0.06 & Gan et al. (2010) \\
\hline
\end{tabular}

was lower than the class I sediment category and higher than the TEL. The arsenic content of the sediment core changed little.

Mercury contents of the intertidal sediment core from the Pearl River Estuary in Guangdong ranged from 0.03 to $0.39 \mathrm{mg} / \mathrm{kg}$ with an average concentration of $0.25 \mathrm{mg} / \mathrm{kg}$ (Fig. 2 and Table 3), which was higher than the class I sediment category and the TEL. This indicated that the Pearl River Estuary sediment was polluted by mercury and would pose negative biological effects to the aquatic system. The mercury content was about $0.20 \mathrm{mg} / \mathrm{kg}$ in the depth of 0 to $42 \mathrm{~cm}$, it was about $0.04 \mathrm{mg} / \mathrm{kg}$ in the depth of 42 to $50 \mathrm{~cm}$, it was about $0.30 \mathrm{mg} / \mathrm{kg}$ in the depth of 50 to $112 \mathrm{~cm}$, and it changed little within each of the three depth ranges. Arsenic contents ranged from 10.62 to $41.35 \mathrm{mg} / \mathrm{kg}$ with an average concentration of $26.11 \mathrm{mg} / \mathrm{kg}$ (Fig. 3 and
Table 3), higher than the class I sediment category and the TEL. The arsenic content was low (10.62 to $33.44 \mathrm{mg} / \mathrm{kg}$ ) within the depth range of 0 to $56 \mathrm{~cm}$ and higher ( 35.32 to $41.35 \mathrm{mg} / \mathrm{kg}$ ) within the depth range of 56 to $112 \mathrm{~cm}$. Similar to the previous studies (Chen et al. 2016; Wang et al. 2015c; Ye et al. 2012), the content of $\mathrm{Hg}$ and As elevates from $60 \mathrm{~cm}$ towards the bottom of the core, which might result from the more environment protection activities and less pollution from human and industrial activities during these years.

This study also compared mercury and arsenic contents from sediment samples across seven typical intertidal zones in China with results from other regions worldwide (Table 4). Mercury and arsenic contents were similar for the Liaohe River Estuary both in this study and the previous study, as the reference values have shown. Contents differed slightly from this study and

Table 4 Concentrations of $\mathrm{Hg}$ and $\mathrm{As}$ in different regions from other studies

\begin{tabular}{|c|c|c|c|c|c|}
\hline \multirow[t]{2}{*}{ Sampling site } & \multicolumn{2}{|l|}{ As $(\mathrm{mg} / \mathrm{kg})$} & \multicolumn{2}{|l|}{$\mathrm{Hg}(\mathrm{mg} / \mathrm{kg})$} & \multirow[t]{2}{*}{ Reference } \\
\hline & Range & Mean & Range & Mean & \\
\hline Liaohe River Estuary & $2.76-24.50$ & 8.13 & $0.01-0.80$ & 0.07 & Bi et al. (2017) \\
\hline Jiaozhou Bay & $10.00-20.80$ & & $0.12-0.58$ & & Liu et al. (2017) \\
\hline Yellow River Delta & $6.20-17.20$ & 9.47 & $0.02-0.10$ & 0.04 & Cheng et al. (2017) \\
\hline Yangtze River mouth & $4.66-65.60$ & 13.51 & $0.01-0.09$ & 0.03 & Hu et al. (2015) \\
\hline Minjiang River Estuary & $2.39-14.48$ & 8.83 & $0.00-0.22$ & 0.05 & Bi et al. (2017) \\
\hline Pearl River Estuary & $1.93-39.49$ & 21.90 & $0.01-0.26$ & 0.14 & Bi et al. (2017) \\
\hline Asalyeh part & $1.50-9.30$ & 3.70 & $0.03-0.37$ & 0.12 & Delshab et al. (2017) \\
\hline Brisbane River Estuary & $2.40-5.20$ & $3.90 \pm 0.90$ & $0.01-0.90$ & $0.40 \pm 0.02$ & Duodu et al. (2017) \\
\hline
\end{tabular}


the previous one for the Yangtze River Estuary and the Pearl River Estuary, however, which may be due to the different sampling sites and times. Concentration ranges observed in this study were similar to those from Jiaozhou Bay, the Yellow River Delta, and the Minjiang River Estuary, but were clearly higher than those from Asalyeh and the Brisbane River Estuary.

Contamination levels of heavy metals

Numerous indices have been proposed for quantifying the degree of heavy metal contamination in sediment. This study selected two types of indices ( $I_{\text {geo }}$ and EF) to assess the degree of heavy metal contamination in the sediment cores.

The geoaccumulation index $\left(I_{\text {geo }}\right)$ is a common parameter used to assess the metal contamination in sediments with a corresponding natural background level as a reference (Müller 1969; Najamuddin et al. 2016; Williams and Block 2015):

$I_{\text {geo }}=\log _{2}\left[\mathrm{C}_{\mathrm{n}} /\left(1.5 \times \mathrm{B}_{\mathrm{n}}\right)\right]$

where $C_{n}$ is the concentration of metal (n) in the sample and $B_{n}$ is the geochemical background concentration of metal (n). (The $\mathrm{B}_{\mathrm{n}}$ of $\mathrm{Hg}$ and $\mathrm{As}$ in different areas are listed in Table 3.) The factor (1.5) is a background matrix correction factor attributed to the lithogenic effect. $I_{\text {geo }}$ is classified into seven levels: unpolluted $\left(I_{\text {geo }} \leq\right.$ 0 ), unpolluted to moderately polluted $\left(0<I_{\mathrm{geo}} \leq 1\right)$, moderately polluted $\left(1<I_{\text {geo }} \leq 2\right)$, moderately to strongly polluted $\left(2<I_{\text {geo }} \leq 3\right)$, strongly polluted $\left(3<I_{\text {geo }} \leq 4\right)$, strongly to extremely polluted $\left(4<I_{\text {geo }} \leq 5\right)$, and extremely polluted $\left(I_{\text {geo }}>5\right)$.

As shown in Fig. 4, the $I_{\text {geo }}$ values for $\mathrm{Hg}$ were below zero in the sediments from the Daliao River Estuary, the Jianhe River, Yancheng Shoal, and the Dongtan Yangtze River, which indicated that the above areas were uncontaminated by $\mathrm{Hg}$. The $I_{\text {geo }}$ values for $\mathrm{Hg}$ ranged between 0 and 1 in sediments from the Dagu River Estuary and Hangzhou Bay, indicating mild levels of pollution. The $I_{\text {geo }}$ values for $\mathrm{Hg}$ were in the range of 1 and 2 in the Pearl River Estuary, which demonstrated moderate levels of contamination.

As shown in Fig. 4, the $I_{\text {geo }}$ values for As in the Pearl River Estuary were between 0 and 1, which revealed mild pollution levels; $I_{\text {geo }}$ values for As in the other study areas were lower than 0 , demonstrating that they were unpolluted.

The potential ecological risk factor $\left(\mathrm{E}_{\mathrm{r}}^{\mathrm{i}}\right)$ was used to assess the potential ecological risk of heavy metals in sediment and was initially introduced by Håkanson (1979). This method not only assesses the pollution status in sediments but also combines potential ecological and environmental effects with toxicology, providing a better evaluation of the potential risk of heavy metal contamination with the index level. The potential ecological risk factor of a given metal $\left(\mathrm{E}_{\mathrm{r}}^{\mathrm{i}}\right)$ is defined as

$E_{r}^{i}=T_{r}^{i} \times C_{r}^{i}=T_{r}^{i} \times\left(C_{0}^{i} / C_{n}^{i}\right)$

where $E_{r}^{i}$ is the potential ecological risk for a given element $\mathrm{i}$; $\mathrm{T}_{\mathrm{r}}^{\mathrm{i}}$ is the toxic response factor (the $\mathrm{T}_{\mathrm{r}}^{\mathrm{i}}$ of As
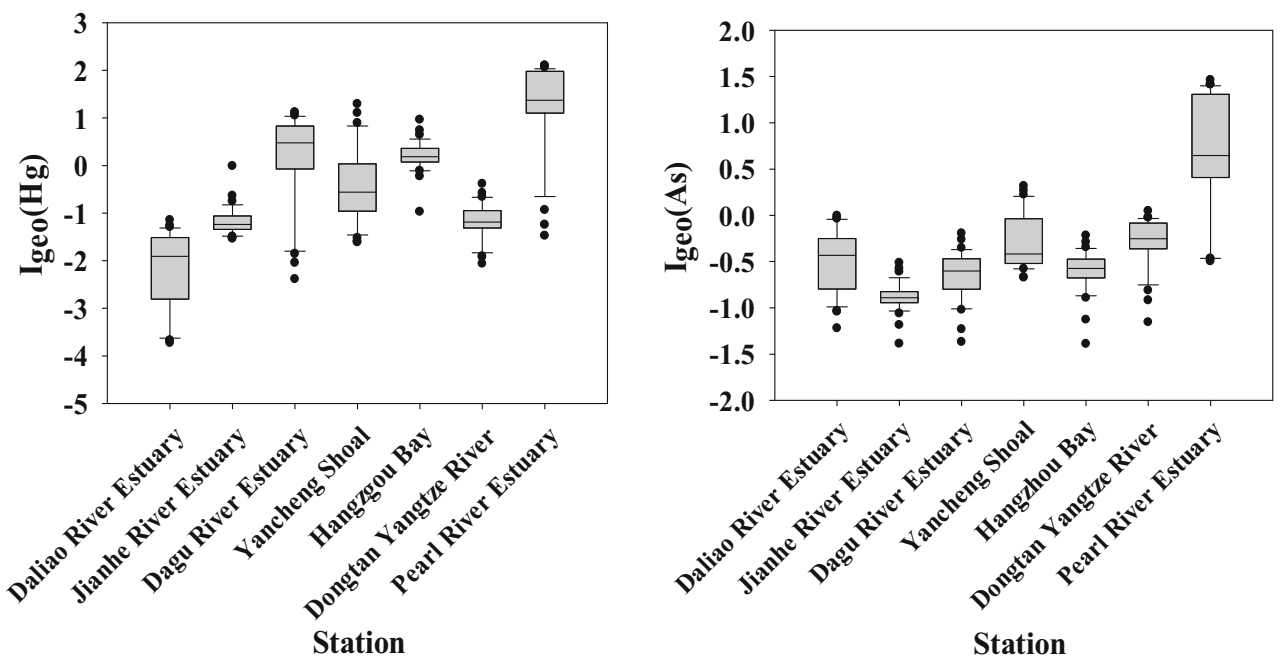

Fig. 4 The $I_{\text {geo }}$ values of $\mathrm{Hg}$ and As in sediment cores from seven typical intertidal zones 

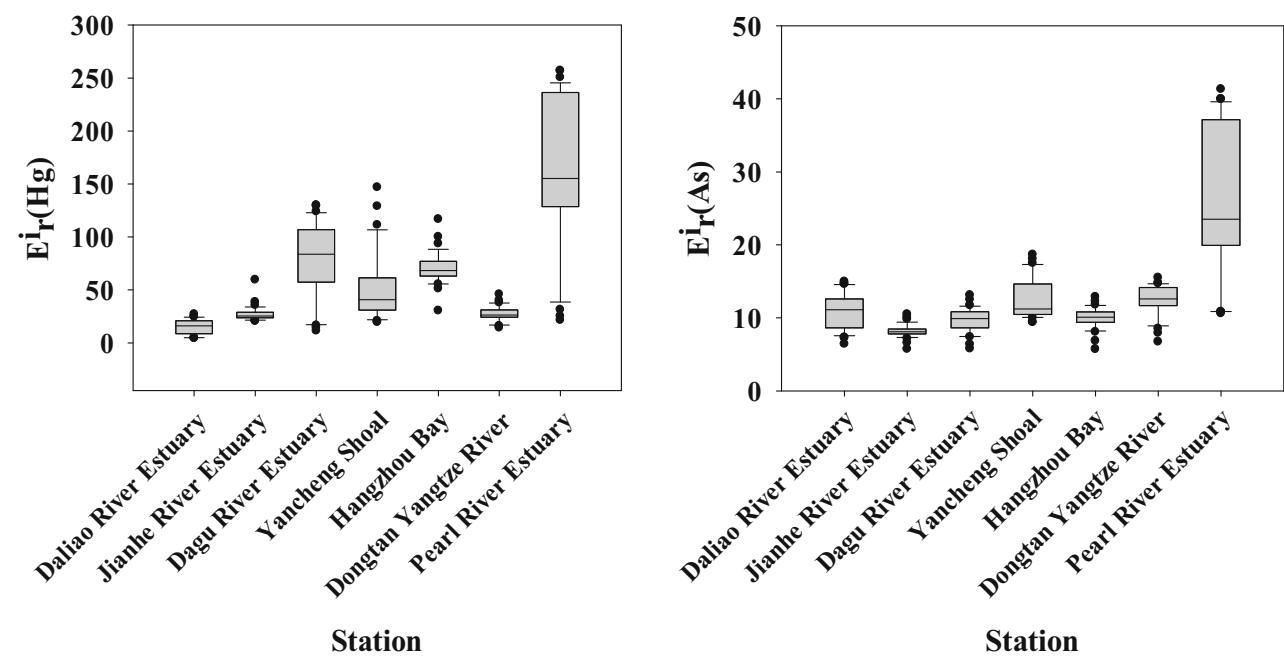

Fig. 5 The $\mathrm{E}_{\mathrm{r}}^{\mathrm{i}}$ values of $\mathrm{Hg}$ and $\mathrm{As}$ in sediment cores sediment cores from seven typical intertidal zones

is 10; the $\mathrm{T}_{\mathrm{r}}^{\mathrm{i}}$ of $\mathrm{Hg}$ is 40 ); and $\mathrm{E}_{\mathrm{f}}^{\mathrm{i}}$, $\mathrm{E}_{0}^{\mathrm{i}}$, and $\mathrm{E}_{\mathrm{n}}^{\mathrm{i}}$ are the contamination factor, the concentration in sediment, and the background reference level for element $i$, respectively. $E_{r}^{i}$ is classified into five levels: low risk $\left(E_{r}^{i}<40\right)$, moderate risk $\left(40 \leq \mathrm{E}_{\mathrm{r}}^{\mathrm{i}}<80\right)$, considerate risk $\left(80 \leq \mathrm{E}_{\mathrm{r}}^{\mathrm{i}}<\right.$ $160)$, high risk $\left(160 \leq \mathrm{E}_{\mathrm{r}}^{\mathrm{i}}<320\right)$, and very high risk $\left(\mathrm{E}_{\mathrm{r}}^{\mathrm{i}} \geq 320\right)$.

As shown in Fig. 5, the values of $\mathrm{E}_{\mathrm{r}}^{\mathrm{Hg}}$ in the Daliao River Estuary, the Jianhe River Estuary, and the Dongtan Yangtze River ranged between 0 and 40, which showed that there was a low environmental risk; values of $E_{r}^{\mathrm{Hg}}$ in the Dagu River Estuary and Yancheng Shoal ranged from 40 and 80 , representative of a moderate potential ecological risk. Values of $\mathrm{E}_{\mathrm{r}}^{\mathrm{Hg}}$ in the Pearl River Estuary ranged between 80 and 160, indicating a strong potential ecological risk. The evaluation results of $\mathrm{E}_{\mathrm{r}}^{\mathrm{Hg}}$ were similar to those of $I_{\text {geo. }}$.

Values of $E_{r}^{A s}$ in the seven study areas were all less than 40 , indicating mild potential ecological risks and posing fewer negative environmental effects when compared with $\mathrm{Hg}$.

\section{Conclusions}

The vertical profiles, contamination levels, and potential risks of mercury and arsenic from seven typical intertidal sediment cores in China were presented in this study. Results showed that contents of 4mercury and arsenic in sediment cores from the Pearl River Estuary were greater than the class I sediment category, whereas the content from other study areas were all lower than the class I sediment category, which indicated that the Pearl River Estuary was more likely influenced by nearby industrial and tourism impacts. The mercury contents from the study areas were all lower than the TEL except for the Pearl River Estuary, indicating that some adverse effects on biota due to mercury would probably be observed there. Arsenic contents were all greater than the TEL, indicating that negative biological effects due to arsenic may be observed in the study areas. The Pearl River Estuary was moderately polluted by mercury and had a strong potential ecological risk; other areas were uncontaminated or mildly contaminated, and had a low or moderate potential ecological risk. The Pearl River Estuary was mildly polluted by arsenic and had a mild potential risk, while other areas were unpolluted and had a mild potential risk. This study provided some baseline information for further research in the study areas.

Acknowledgements This research was financially supported by the Youth Innovation Promotion Association (2011170) and the Equipment Development Project (YZ201558) of Chinese Academy of Sciences, and the Basic Survey of the Ministry of Science and Technology (2014FY10600). We thank MogoEdit for its linguistic assistance during the preparation of this manuscript. Additionally, the concentration of TOC and the sedimentation rate in sediment cores of this study and the grain size in sediment cores of the Dongtan Yangtze River Estuary and Hangzhou Bay are provided by Prof. Dongqi Wang (East China Normal University). The grain size in sediment cores of Liaohe River Estuary, the Jianhe River Estuary, and Yancheng Shoal are provided by Dr. Aiping Feng and Dr. Peng Xia (State Oceanic Administration). The grain size in sediment cores of the Dagu River Estuary are provided by Dr. Guohua Hou (Qingdao Institute of Marine Geology). The grain size in sediment cores of the Pearl River Estuary 
are provided by Prof. Dongyan Liu (East China Normal University) and Dr. Yujue Wang (Yantai Institute of Coastal Zone Research). We thank these participators for the supply of the data, which make this study more integrated and more meaningful.

\section{References}

AQSIQ (General Administration of Quality Supervision, inspection and quarantine of the People's Republic of China) (2007). The speciation for marine monitoring-parting 5: sediment analysis (GB 17378.5-2007). Standards Press of China (in Chinese).

Araujo, B. F., Hintelmann, H., Dimock, B., Almeida, M. G., \& Rezende, C. E. (2017). Concentrations and isotope ratios of mercury in sediments from shelf and continental slope at Campos Basin near Rio de Janeiro, Brazil. Chemosphere, $178,42-50$.

Benzer, S. (2017). Concentrations of arsenic and boron in water, sediment and the tissues of fish in Emet stream (Turkey). Bulletin of Environmental Contamination and Toxicology, 98(6), 805-810.

Bi, S., Yang, Y., Xu, C., Zhang, Y., Zhang, X., \& Zhang, X. (2017). Distribution of heavy metals and environmental assessment of surface sediment of typical estuaries in eastern China. Marine Pollution Bulletin, 121(1-2), 357-366.

Centor, C. N. E. M. (1990). Chinese elemental background values for soils. Beijing: Chinese Environmental Science Press.

Chai, X. P., Hu, B. L., \& Wei, N. (2015). Distribution, sources and assessment of heavy metals in surface sediments of the Hangzhou Bay and its adjacent areas. Acta Scientiae Circumstantiae, 35(12), 3906-3916 (in Chinese).

Chen, C. F., Ju, Y. R., Chen, C. W., \& Dong, C. D. (2016). Vertical profile, contamination assessment, and source apportionment of heavy metals in sediment cores of Kaohsiung Harbor, Taiwan. Chemosphere, 165, 67-79.

Cheng, Q., Lou, G., Huang, W., \& Li, X. (2017). Assessment and potential sources of metals in the surface sediments of the Yellow River Delta, eastern China. Environmental Science and Pollution Research International, 24(21), 17446-17454.

Delshab, H., Farshchi, P., \& Keshavarzi, B. (2017). Geochemical distribution, fractionation and contamination assessment of heavy metals in marine sediments of the Asaluyeh port, Persian gulf. Marine Pollution Bulletin, 115(1-2), 401-411.

Duan, L., Song, J., Yuan, H., Li, X., \& Li, N. (2013). Spatiotemporal distribution and environmental risk of arsenic in sediments of the East China Sea. Chemical Geology, 340, 21-31.

Duodu, G. O., Goonetilleke, A., \& Ayoko, G. A. (2017). Potential bioavailability assessment, source apportionment and ecological risk of heavy metals in the sediment of Brisbane River estuary, Australia. Marine Pollution Bulletin, 117(1-2), 523531.

Flemming, B. W., \& Delafontaine, M. T. (2000). Mass physical properties of muddy intertidal sediments: some applications, misapplications and non-applications. Continental Shelf Research, 20, 1179-1197.
Gan, H. Y., Liang, K., \& Zheng, Z. C. (2010). Background values, contamination assessment and zoning of heavy metals in sediments of the Pearl River estuary. Earth and Environment, 38(3), 344-350.

Gao, L., Gao, B., Xu, D., Peng, W., Lu, J., \& Gao, J. (2017). Assessing remobilization characteristics of arsenic (As) in tributary sediment cores in the largest reservoir, China. Ecotoxicology and Environmental Safety, 140, 48-54.

Gu, Y. G., \& Lin, Q. (2016). Trace metals in a sediment core from the largest mariculture base of the eastern Guangdong coast, South China: vertical distribution, speciation, and biological risk. Marine Pollution Bulletin, 113(1-2), 520-525.

Håkanson, L. (1979). An ecological risk index for aquatic pollution control-a sedimentological approach. Water Research, 14, 975-1001.

Hu, G., Bi, S., Xu, G., Zhang, Y., Mei, X., \& Li, A. (2015). Distribution and assessment of heavy metals off the Changiiang River mouth and adjacent area during the past century and the relationship of the heavy metals with anthropogenic activity. Marine Pollution Bulletin, 96(1-2), 434-440.

Jiang, H. Y., Liu, X. B., Zhang, Q. F., R., H., Liu, Y., Bo, W. J., \& Wang, Q. (2012). Distribution and risk analysis of heavy metals and as in the surface sediment of Tianjin offshore area. Marine Sciences, 37(9), 82-89.

Kumar, A., Singhal, R. K., Rout, S., \& Ravi, P. M. (2013). Spatial geochemical variation of major and trace elements in the marine sediments of Mumbai Harbor bay. Environmental Earth Sciences, 70(7), 3057-3066.

Li, Y., \& Li, H. G. (2017). Historical records of trace metals in core sediments from the Lianyungang coastal sea, Jiangsu, China. Marine Pollution Bulletin, 116(1-2), 56-63.

Liu, R., Men, C., Liu, Y., Yu, W., Xu, F., \& Shen, Z. (2016). Spatial distribution and pollution evaluation of heavy metals in Yangtze estuary sediment. Marine Pollution Bulletin, 110(1), 564-571.

Liu, X., Zhang, L., \& Zhang, L. (2017). Concentration, risk assessment, and source identification of heavy metals in surface sediments in Yinghai: a shellfish cultivation zone in Jiaozhou Bay, China. Marine Pollution Bulletin, 121(1-2), 216-221.

Long, R. E., \& MacDonald, D. D. (1995). Incidence of adverse biological effects within ranges of chemical concentrations in marine and estuary sediments. Environmental Management, 19, 81-97.

Ma, L., Yang, X. B., Tong, C. Y., Wu, A. J., \& Liu, M. H. (2008). The geochemical characteristics of heavy metal elements in sediments of Hunhe drainage area in Liaoning Province. Rock and Minarel Analysis, 27(3), 184-188.

Müller, G. (1969). Index of geo accumulation in sediments of the Rhine River. GeoJournal, 2, 108-118.

Najamuddin, T. P., Sanusi, H. S., \& Wayan Nurjaya, I. (2016). Seasonal distribution and geochemical fractionation of heavy metals from surface sediment in a tropical estuary of Jeneberang River, Indonesia. Marine Pollution Bulletin, $111,456-462$.

Qian, X., Liang, B., Fu, W., Liu, X., \& Cui, B. (2016). Polycyclic aromatic hydrocarbons (PAHs) in surface sediments from the intertidal zone of Bohai Bay, northeast China: spatial distribution, composition, sources and ecological risk assessment. Marine Pollution Bulletin, 112(1-2), 349-358. 
Sarasiab, A. R., Hosseini, M., \& Mirsalari, Z. (2014). Mercury distribution in contaminated surface sediments from four estuaries, Khuzestan shore, north part of Persian gulf. Bulletin of Environmental Contamination and Toxicology, 93(5), 522-525.

SEPA (2002). Marine sediment quality(GB 18668-2002). Standards Press of China.

Tao, Z. K., Bi, C. J., Chen, Z. L., \& Wang, X. H. (2014). Pollution characteristics and assessment of heavy metals in the sediemnts from Dishui Lake. Resuorces and Environment in the Yantze Basin, 23(12), 1717-1720 (in Chinese).

Traverso-Soto, J. M., Lara-Martin, P. A., Gonzalez-Mazo, E., \& Leon, V. M. (2015). Distribution of anionic and nonionic surfactants in a sewage-impacted Mediterranean coastal lagoon: inputs and seasonal variations. The Science of the Total Environment, 503-504, 87-96.

Wang, Z. H., Feng, J., \& Nie, X. P. (2015). Recent environmental changes reflected by metals and biogenic elements in sediments from the Guishan Island, the Pearl River estuary, China. Estuarine, Coastal and Shelf Science, 164, 493-505.

Wang, H., Liu, R., Wang, Q., Xu, F., Men, C., \& Shen, Z. (2016a). Bioavailability and risk assessment of arsenic in surface sediments of the Yangtze River estuary. Marine Pollution Bulletin, 113(1-2), 125-131.
Wang, J., Liu, G., Zhang, J., Liu, H., \& Lam, P. K. (2016b). A 59year sedimentary record of metal pollution in the sediment core from the Huaihe River, Huainan, Anhui, China. Environmental Science and Pollution Research International, 23(23), 23533-23545.

Williams, N., \& Block, K. A. (2015). Spatial and vertical distribution of metals in sediment cores from Río Espíritu Santo estuary, Puerto Rico, United States. Marine Pollution Bulletin, 100, 445-452.

Ye, F., Huang, X. P., Zhang, D. W., Tian, L., \& Zeng, Y. Y. (2012). Distribution of heavy metals in sediments of the Pearl River estuary, southern China: implications for sources and historical changes. Journal of Environmental Sciences, 24(4), 579588 .

Zhang, W., Cao, F., Yang, L., Dai, J., \& Pang, X. (2017). Distribution, fractionation and risk assessment of mercury in surficial sediments of Nansi Lake, China. Environmental geochemistry and health.

Zuo, P., Zhao, S. D., Zhao, X. Q., Teng, H. F., Geng, J. J., \& Gao, X. (2010). Distribution characteristics of heavy metals in surface sediments in original salt marshes in Yancheng, Jiangsu Province, China. Marine Science Bulletin, 29(4), 372-377. 